\title{
ペンタセン超薄膜のエピタキシャル成長と光電子分光
}

\author{
島田敏宏・鈴木維允・大伴真名歩・長谷川哲也 \\ 東京大学大学院理学系研究科化学専攻 傿113-0033 東京都文京区本郷 7-3-1
}

（2008 年 9 月 10 日受理）

\section{Epitaxial Growth and Photoelectron Spectroscopy of Pentacene}

\author{
Toshihiro Shimada, Tadamasa Suzuki, Manabu Онтомо and Tetsuya Hasegawa \\ Department of Chemistry, The University of Tokyo \\ 7-3-1 Hongo, Bunkyo-ku, Tokyo 113-0033
}

(Received September 10, 2008)

\begin{abstract}
We developed a technique to prepare highly ordered thin films of organic molecular semiconductors. A quasi single crystalline monolayer of thin film phase pentacene was epitaxially grown on a substrate with a nm scale template prepared by step bunching of $\operatorname{Si}(111)$ surface. Band dispersion of the films was measured by angle resolved photoelectron spectroscopy at different temperatures and transfer integrals were derived from tight binding fit to the dispersion observed at $130 \mathrm{~K}$. When the temperature was elevated to $300 \mathrm{~K}$ the second derivative plot of the photoelectron spectra became broader and the band dispersion was lost in two directions, whereas the dispersion was still observed in one direction. This finding suggests the anisotropy in phonon scattering, which determines the carrier mobility in the organic semiconductors at room temperature.
\end{abstract}

KEYWORDS : organic semiconductor, epitaxial growth, step bunching, band dispersion, pentacene

\section{1.は じめに}

有機半導体は有機発光ダイオード（OLED）をはじめ として実用化が進んでいるが，無機物に比べて移動度が 低いことが常に問題となっている。分光測定により，移 動度を決める要因が何であるかを明らかにし, 高移動度 物質の設計指針を与えることは重要である。例えば，角 度分解光電子分光によりさまざまな有機半導体結晶のバ ンド構造を決定する研究は有効であると考える。数年前 までそのような研究がほとんどなかった原因としては, 有機半導体の大面積単結晶が得にくかったこと, 電子線 照射ダメージやチャージアップを防ぎながら表面構造解 析や電子分光を行う方法が知られていなかったことがあ げられるであろう。

この問題を避けて測定用の試料を用意する方法として は，有機分子のエピタキシャル成長を行うことが考えら れる。しかし, 有機低分子の結晶格子は対称性が低く,

E-mail : shimada@chem.s.u-tokyo.ac.jp
多くの場合エネルギーの近い結晶多形が存在するため, ヘテロエピタキシャル成長が起こる場合でも配向や構造 の異なる多配向構造をとり，基板上で配向の揃った均一 な厚みを持つ結晶薄膜を得るのは容易ではない。

ここで紹介する実験においては, 微傾斜研磨した単結 晶基板表面の周期的ステップを利用し, さらに適切な表 面不活性化を施すことにより結晶方位がほぼ単一に揃っ たペンタセン薄膜を作製した。さらに，室温（300 K） と低温 $(130 \mathrm{~K})$ において角度分解光電子分光を測定し てフォノン散乱に異方性があることを示唆する結果を得 た。

\section{2. 基板表面のステップによる薄膜相ペンタセ ンの擬似単一配向エピタキシャル成長}

有機半導体結晶中のキャリヤ移動度の上限を決める因 子については, 柔らかいファンデルワールス結晶である ことからくる激しいフォノン（格子振動）散乱が有力な 候補の一つであるが1,2), まだ物質ごとの定量的な検討 はほとんどなされていない。フォノン散乱を分子の立場 
から見ると, 分子間の振動により分子位置の周期性が失 われるとキャリヤの運動量がよい量子数でなくなり，k 空間におけるバンド分散が消失するという理解ができ る。フォノン散乱の効果の詳細を調べるため, 代表的な $\mathrm{p}$ 型有機半導体であるペンタセンのバンド分散を温度を 変えて測定するための実験を行った。

バンド分散を測定するためには, 単結晶か, 単一配向 した薄膜の角度光電子分光 (Angle Resolved Photoelectron Spectroscopy : ARPES) を行うのが正統的な方法で ある。ダングリングボンドを水素や Bi で終端化した $\mathrm{Si}$ （111）の平坦表面上にはペンタセンが分子長軸を立てた 構造でエピタキシャル成長が起こる ${ }^{3,4)}$ 。基板とペンタ センの対称性が異なるために, 平坦な $\sqrt{3} \times \sqrt{3}-\mathrm{Bi}$ 終端 化表面では Fig. 1 (a) の低速電子線回折（Low Energy Electron Diffraction : LEED) 像のように等価な 6 方向に 配向した結晶が得られる。格子定数は LEED と表面 $\mathrm{X}$ 線回折から $a=0.593 \mathrm{~nm}, b=0.759 \mathrm{~nm}, \gamma=90^{\circ}$ と求めら れ, ペンタセンの $\{210\}$ 軸が, 基板 $\mathrm{Si} の \quad\{1 \overline{1} 0\}$ 軸に 平行になっている (“line-on-line” 整合4) ${ }^{4}$ 。水素終端化 表面上では「バルク相ペンタセン」が, $\sqrt{3} \times \sqrt{3}-\mathrm{Bi}$ 終
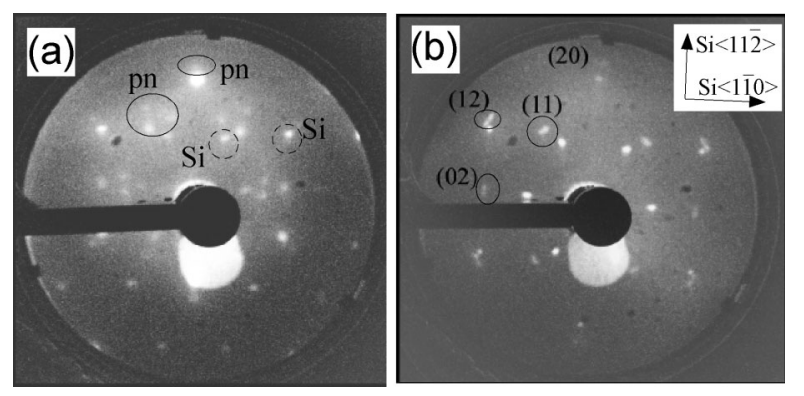

Fig. 1. LEED images of epitaxially grown pentacene films. (a) Grown on flat $\sqrt{3} \times \sqrt{3}$ Bi-terminated $\mathrm{Si}(111)$. (b) Grown on step-bunched $2^{\circ}$-off $\sqrt{3} \times \sqrt{3} \mathrm{Bi}$ terminated $\mathrm{Si}$ (111). The thickness was submonolayer for both images. "Si" and "pn" denotes diffraction from the substrate and the pentacene film, respectively.
端化表面上では「薄膜相 (thin film phase)」ペンタセン が成長する。この 2 つの相は, 分子の傾きがわずかに異 なるへリングボーン構造であるが, 基板によってこのよ うなつくりわけが起こる原因はまだわかっていない。

このような試料では, ARPESの結果は異なる方向を 持つ結晶からの寄与が混じってしまい, 解析が困難とな る。一方, 今回我々が開発した基板表面を用いて成長す ると配向が Fig. 1（b）に示すようにほぼ 1 方向（双晶 を含む）に制限されていることがわかる。

この手法は, さまざまな基板の上にペンタセンの蒸着 を試み, 基板上に存在するステップを利用する我々が過 去に提案した方法 ${ }^{5}$ を発展させものである。具体的に は, 斜めに研磨した Si (111) 単結晶を超高真空中で加 熱して原子層ステップが重畳したステップバンチングを 起こさせ, 表面のダングリングボンドを Bi で $\sqrt{3} \times \sqrt{3}$ 終端した表面を用いている6,7)。Table 1 に示すように, このようにして作製した基板表面は冷却条件によりステ ップ高さを $\mathrm{nm}$ スケールで制御できる。この基板を用い てペンタセンを蒸着すると, Fig. 2 の原子間力顕微鏡 (Atomic Force Microscope : AFM) 像に示すように 1.5〜2 $\mathrm{nm}$ 以上のステップ高さがある場合に，ステップからの 影響を受けて成長している様子が見られる。この高さは ペンタセン 1 分子層の高さ (約 $1.5 \mathrm{~nm}$ ) に相当し, LEED による擬似単一配向が得られるステップ高さと一 致している。この AFM 像と, ここでは示していない RHEED 像から判断すると, 膜の $\mathrm{ab}$ 面は基板のテラス に平行になっている。

配向の機構を考える。一つの候補は, ステップ端では 隣の分子が存在しない結晶の端ができるため, 安定な端 を持つ配向が生じているのではないかというものであ

Table 1. Step height of step-bunched Bi-Si (111) substrates obtained with various cooling rate.

\begin{tabular}{lcrl}
\hline Cooling rate $\left({ }^{\circ} \mathrm{C} / \mathrm{min}\right)$ & Quench & 20 & 5 \\
Step height $(\mathrm{nm})$ & $<0.5$ & 1 & 3 \\
\hline
\end{tabular}

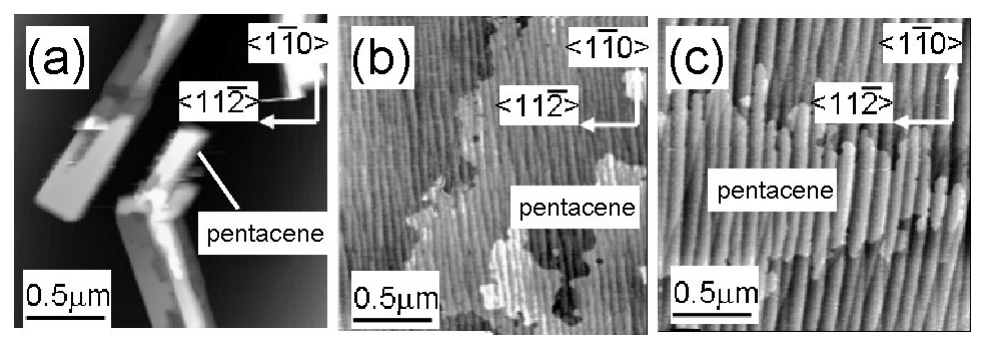

Fig. 2. AFM images of pentacene films grown on $2^{\circ}$-off $\sqrt{3} \times \sqrt{3}$ Biterminated $\mathrm{Si}$ (111). (a) Quenched from $7 \times 7$ structure. (b) cooling rate $20^{\circ} \mathrm{C} / \mathrm{min}$. (c) cooling rate $5^{\circ} \mathrm{C} / \mathrm{min}$. The substrate temperature during the deposition was $60^{\circ} \mathrm{C}$. 
Table 2. Edge energy of a pentacene monolayer.

\begin{tabular}{lllllllll}
\hline Edge face & $(010)$ & $(130)$ & $(120)$ & $(110)$ & $(210)$ & $(310)$ & $(100)$ \\
Energy $\left(\mathrm{Jm}^{-2}\right)$ & 0.186 & 0.203 & 0.202 & 0.189 & 0.215 & 0.219 & 0.245 \\
\hline
\end{tabular}

る。端の安定性を調べるために分子力学計算で薄膜相ぺ ンタセン単分子層クラスターの端面のエネルギーを計算 した。 $4.2 \mathrm{~nm}$ のペンタセンの単分子層の円盤をつくり, 円盤をさまざまな結晶面で切断して, 分子力場に $\mathrm{MM}^{8,9)}$ を用いてエネルギーの増加を計算した。結果を Table 2 に示す。我々が得た配向（(100）面で切断）で は端のエネルギーがもっとも高くなることがわかり，単 純なペンタセンの端の安定性による機構は否定された。 真の機構が何かはまだわかっていないが，ヒントとなる 実験事実として, Fig. 2 (c) の AFM 像でペンタセンの 単層膜がステップを越えてつながっていることを指摘し たい。ステップ上端（壁）の Bi-Si とペンタセンの相互 作用による特定方位の結晶核の安定化が重要なのではな いかと考える。また，ステップ端での分子の運動方向の 制限による動的な要因 ${ }^{10)}$ 考慮する必要があろう。

\section{3. バンド分散測定一温度依存性とその解釈}

前節で述べたように，擬似単一配向したペンタセン薄 膜の結晶構造は,「薄膜相」であった。2 $1.2 \mathrm{eV}$ の He-I 紫外光を用いた ARPES の結果を Fig. 3 に示す。測定に は旧 VG 社の ADE4S-400を用いている。Fig. 3 (a), (b) はそれぞれ $130 \mathrm{~K}, 300 \mathrm{~K}$ で得られたものである。 Fig. 3 (a) の $130 \mathrm{~K}$ で測定したバンド分散に対する強結 合近似によるフィッティングにより transfer integral（移 動積分）が Table 3 のように求まる。バンド頂上（この 結果からは $\Gamma-Y$ 中間点）における有効質量は $0.8 \sim 0.9$ $m_{0}$ （ $m_{0}$ は電子の静止質量）となった。基板の $\mathrm{Bi}-\mathrm{Si}$ と の相互作用があることは否定できず，また有限温度にお ける分子間振動の影響が $130 \mathrm{~K}$ では残っていることにも 注意しなければならないが，配向試料を用いることによ り有機半導体の電子状態についてこのような精密な議論 が可能になる。

また, Fig. 3（b）から，300 K で測定した ARPES は 強度分布がぼやけ，分散も失われているが， $\Gamma$-X 方向は 分散が残っている様子が観察された。この原因について は，分子間の熱振動によって波動関数のコヒーレンスが 失われる方向に強い異方性があることが考えられる。 Troisi らは，バンド分散を与える分子間移動積分に異方 性があることを分子動力学シミュレーションの結果から 指摘している。Fig. 4 に，文献 10）に数值として与えら れている分子間移動積分の半值幅の温度変化をグラフ化 して示す。 $\Gamma$-X 方向に対応する $\mathrm{A}$ および $\mathrm{A}^{\prime}$ 方向で半值 (a)

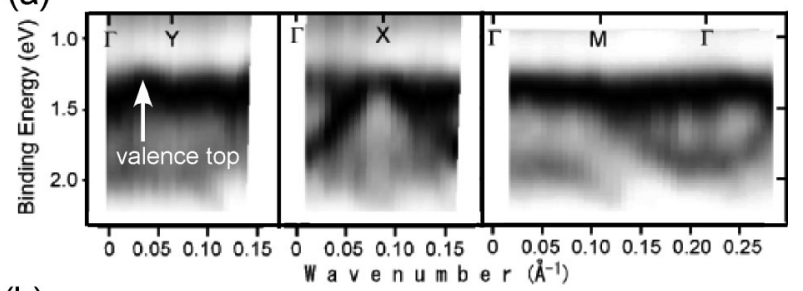

(b)

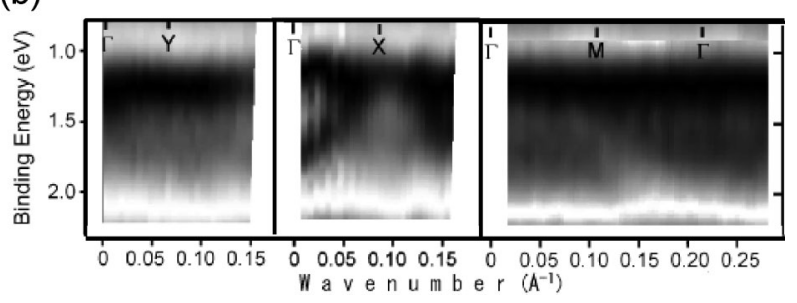

Fig. 3. Band dispersion of a quasi-single crystalline pentacene monolayer formed on step bunched $\sqrt{3} \times \sqrt{3}$ Bi-terminated $\mathrm{Si}(111)$ obtained from angle resolved photoelectron spectroscopy (ARPES). The photon energy was $21.2 \mathrm{eV}$. The gray scale images were obtained from the second derivative of the ARPES data. The dark color corresponding to high density of states. (a) at $130 \mathrm{~K}$. (b) at $300 \mathrm{~K}$.

Table 3. Transfer integral values corresponding to the molecular interaction shown in Fig. 4 inset.

\begin{tabular}{lccc}
\hline Interaction in Fig. 4 & A $=$ A $^{\prime}$ & B & C \\
Transfer integral $(\mathrm{meV})$ & -25 & 65 & 70 \\
\hline
\end{tabular}

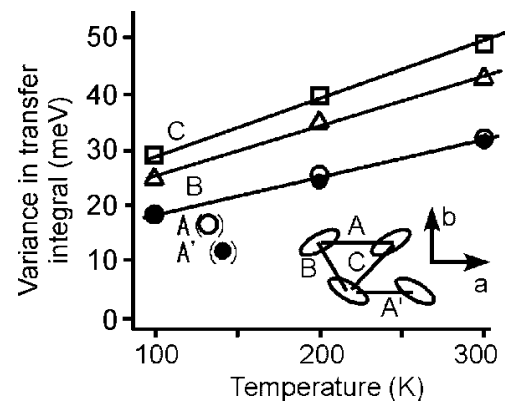

Fig. 4. Temperature dependence of the variance of transfer integrals plotted by using the values reported in Ref. 11).

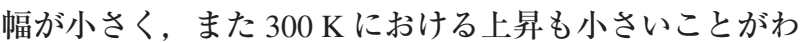
かる。

ペンタセンの他の結晶形に対する ARPES については いくつか報告があるが ${ }^{12,13)}$, 温度変化の方向依存性の詳 細な解析はここに述べた結果が初めてである。今後さま ざまな有機半導体について同様の研究を進めることによ り，高い移動度を得るための分子設計につながることを 期待している。 


\section{4. お りに}

有機半導体の単一配向薄膜を得る方法の一つとして, ここで示したように, ステップバンチした微傾斜無機単 結晶表面の適切な終端化が有効であると考えられる。今 回ペンタセンについて行った解析を今後さまざまな物質 について行うことにより, 高い移動度を得るための分子 設計指針を与えることが一つの目標である。

\section{謝 辞}

本研究の一部は科研費・基盤研究 B (17360008), 萌 芽研究 (19651048) およびGCOE「理工連携による化学 イノベーション」の助成により行われた。

\section{文献}

1) K. Hannewald, V.M. Stojanovic, J.M.T. Schellekens, P.A. Bobbert, G. Kresse and J. Hafner : Phys. Rev. B 69, 075211 (2004).

2) A. Troisi and G. Orlandi : Phys. Rev. Lett. 96, 088601 (2006).

3) T. Shimada, H. Nogawa, T. Hasegawa, R. Okada, H. Ichikawa, K. Ueno and K. Saiki : Appl. Phys. Lett. 87,
061917 (2005).

4) A. Al-Mahboob, J.T. Sadowski, Y. Fujikawa, K. Nakajima and T. Sakurai : Phys. Rev. B 77, 035426 (2008).

5) T. Shimada, A. Suzuki, T. Sakurada and A. Koma : Appl. Phys. Lett. 68, 2502 (1996).

6) T. Suzuki, T. Shimada, K. Ueno, S. Ikeda, K. Saiki and T. Hasegawa : Mater. Res. Soc. Symp. Proc. 965, S06-19 (2007)

7) T. Suzuki, T. Shimada, K. Ueno, S. Ikeda, K. Saiki, T. Hasegawa, M. Sasaki and K. Inaba : Appl. Phys. Lett. in press.

8) N.L. Allinger, Y.H. Yuh and J-H. Lii : J. Am. Chem. Soc. 111, 8551 (1989).

9) P. Ren and J.W. Ponder: J. Phys. Chem. B 107, 5933 (2003)

10) T. Shimada, H. Ichikawa and K. Saiki : Appl. Phys. Lett. 89, 141912 (2006).

11) A. Troisi and G. Orlandi : J. Phys. Chem. A. 110, 4065 (2006).

12) N. Koch, A. Vollmer, I. Salzmann, B. Nickel, H. Weiss and J.P. Rabe : Phys. Rev. Lett. 96, 156803 (2006).

13) H. Kakuta, T. Hirahara, I. Matsuda, T. Nagao, S. Hasegawa, N. Ueno and K. Sakamoto : Phys. Rev. Lett. 98, 247601 (2007). 